\title{
La conmemoración del Bicentenario de la independencia en Chiapas
}

\section{Amanda Úrsula Torres Freyermuth y Armando Méndez Zárate}

\section{OpenEdition}

\section{Journals}

Edición electrónica

URL: https://journals.openedition.org/ideas/11495

DOI: 10.4000/ideas. 11495

ISSN: 1950-5701

\section{Editor}

Institut des Amériques

\section{Referencia electrónica}

Amanda Úrsula Torres Freyermuth y Armando Méndez Zárate, «La conmemoración del Bicentenario de la independencia en Chiapas», IdeAs [En línea], 18 | 2021, Publicado el 01 octubre 2021, consultado el 21 octubre 2021. URL: http://journals.openedition.org/ideas/11495 ; DOI: https://doi.org/10.4000/ ideas. 11495

Este documento fue generado automáticamente el 21 octubre 2021.

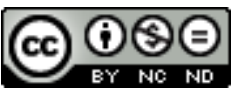

IdeAs - Idées d'Amériques est mis à disposition selon les termes de la licence Creative Commons Attribution - Pas d'Utilisation Commerciale - Pas de Modification 4.0 International. 


\title{
La conmemoración del Bicentenario de la independencia en Chiapas
}

\author{
Amanda Úrsula Torres Freyermuth y Armando Méndez Zárate
}

1 La conmemoración de los 200 años de la consumación de la Independencia de España, de Chiapas y de México, país al que actualmente pertenece esta provincia, se ha visto marcada por dos aspectos: primero, la pandemia mundial provocada por el SARS-CoV-2 y sus efectos en las celebraciones; y segundo, la suspensión de algunos actos y festejos del Bicentenario que fueron desatendidos por las autoridades, pero retomados por iniciativas ciudadanas y académicas. Así, la conmemoración trascurrió entre el silencio e indiferencia de los diferentes niveles de gobierno en Chiapas y el desgano de la sociedad, apesadumbrada por la crisis sanitaria.

\section{Pandemia e impacto social}

2 En México y Chiapas la pandemia mundial se hizo sentir con fuerza durante el verano de 2020. La población experimentó un gran número de contagios y fallecimientos. En el país, entre el 1 de marzo de 2020 al 16 de agosto de 2021 ocurrieron 508447 muertes $^{1}$ consideradas excesos de defunciones ${ }^{2}$. Por si fuera poco, la suspensión y limitación de las actividades económicas, afectó a la economía estatal que se basa en los servicios y el turismo, sectores de los más afectados por la epidemia global. Aún con la crisis sanitaria vigente y en medio de la llamada tercera ola de contagios en México, ocurrieron algunos actos.

Estos trances de emergencia e incertidumbre no coadyuvaron a la celebración del Bicentenario de la consumación de la independencia de Chiapas, prevista en torno a la fecha del 28 de agosto. Al respecto, la actitud gubernamental ante ese suceso histórico y su discurso le ha imprimido un color aún más gris. De este modo, los eventos de celebración popular fueron suspendidos en su totalidad y los "rituales" patrióticos se transmitieron por canales oficiales en Facebook Live y YouTube, realizándose en espacios no vinculados con el poder político - como los palacios de gobierno- y con público limitado. 


\section{Los rituales ausentes de la "mexicanidad" chiapaneca}

Para los habitantes de Chiapas, la Independencia se proclamó en 1810, fecha que marca el inicio del proceso de independencia de México, aunque para ese momento la provincia de Chiapas estaba sujeta a la Capitanía General de Guatemala. El proceso de "mexicanidad" chiapaneca es de largo aliento, con su inicio en 1824 con la incorporación de Chiapas como estado federal mexicano ${ }^{3}$. De este modo, los acontecimientos de 1821 se observan a distancia, a pesar de los esfuerzos académicos y gubernamentales de señalar el inicio de la vida nacional en 1821 con la consumación de la Independencia.

5 Los rituales patrióticos que acompañan cada aniversario de la Independencia en Chiapas comienzan desde el 13 de septiembre, con el acto de conmemoración de la "Gesta Heroica de los Niños Héroes de Chapultepec", durante la invasión estadounidense en México en 1847. Este año, el evento que celebró el 174 aniversario, fue realizado en Tuxtla Gutiérrez a puerta cerrada y con breves discursos, pero transmitido por televisión y redes sociales. ${ }^{4}$. A pesar de ser el 2021 el año del Bicentenario, el acto no se revistió como la apertura de las celebraciones.

6 Al día siguiente, 14 de septiembre, tuvo lugar la conmemoración del 197 aniversario de "la federación de Chiapas a México". Este era uno de los eventos más esperados pues, se reafirma la identidad mexicana de Chiapas marcando distancia con su historia centroamericana. Se trata de una adaptación del discurso histórico, forzando su vínculo con México. Aunque, no hubo eventos académicos que analizaran esta fecha, se espera que, en 2024 con el Bicentenario de ese festejo, se realicen actos especializados que atiendan esa coyuntura. No obstante, el gobernador de Chiapas, Rutilio Escandón Cadenas, con un discurso político de apoyo al gobierno federal, vinculó esta fecha con los logros del proyecto de "Cuarta Transformación" que el presidente Andrés Manuel López Obrador encabeza.

7 En la entidad chiapaneca, el momento culmen de las festividades patrióticas tiene lugar el 15 septiembre por la noche, con el "Grito de Independencia", y el 16 de septiembre, con el desfile cívico militar. Estos dos actos ocurren sin excepción en la mayoría de los pueblos de México y Chiapas. La "noche del Grito" es un punto de encuentro en las plazas públicas para vitorear a los héroes de la Independencia y culminar con tres ¡Viva México! La pandemia impidió estos festejos y el "Grito" desganado fue retransmitido por las redes sociales, sin discursos políticos y sin la rechifla popular a las autoridades encargadas de darlo.

8 Los ánimos de las personas y familias, todavía vestidas de luto por las pérdidas de seres queridos a causa de la pandemia, bajaron los ímpetus festivos y, sumados al desinterés de algunas autoridades municipales que estaban a semanas de abandonar su cargo político, debido a la renovación de ayuntamientos, contribuyeron a que este Bicentenario de la consumación de la Independencia pasara desapercibido y gris.

\section{Chiapas ante su bicentenario}

9 Ante el vacío gubernamental, los festejos de la Independencia fueron promovidos por la sociedad civil y algunos gobiernos municipales. Un grupo de ciudadanos y ciudadanas, ${ }^{5}$ 
interesados en "preservar y difundir los valores históricos, artísticos y culturales del estado", fundaron la Asociación Civil Bicentenario de Chiapas A.C., con el objetivo de promover la memoria histórica de las celebraciones del bicentenario de la independencia de Chiapas en 2021, y del bicentenario de la Federalización de Chiapas a México, en el 2024. En su agenda estaba conmemorar la emancipación de la provincia colonial, resaltando el liderazgo de los chiapanecos por haber sido los primeros políticos de la Capitanía General de Guatemala en pronunciarse en Comitán el 28 de agosto de 1821 a favor de la independencia. En este sentido, Chiapas considera el acta de independencia de Comitán como el inicio del movimiento independentista centroamericano de la Corona española. La Asociación trató de organizar un encuentro regional para reunir a los presidentes de las cinco repúblicas centroamericanas, o en su defecto a sus respectivos embajadores. No obstante, hasta donde tenemos conocimiento, la asociación no encontró respaldo en las autoridades estatales para impulsar ese y otros acontecimientos ${ }^{6}$.

El único evento que se tenía agendado para recordar la adhesión del territorio al Plan de Iguala, tuvo lugar en Comitán el pasado 28 de agosto, en el que se reunieron el presidente de México, el gobernador del estado, el presidente municipal de Comitán y el coordinador nacional de "Memoria Histórica y Cultural de México" Eduardo Villegas Megías, coordinador de Memoria Histórica, recordó que, a principios del siglo xix, Comitán formaba parte de la capitanía general de Guatemala, apuntando su pertenencia a la región centroamericana. También hizo hincapié en que la provincia chiapaneca defendió la causa realista hispana, pues nunca estuvo identificada con el movimiento insurgente de la Nueva España. A pesar de ello, reconoció que "Comitán, Ciudad Real, Tuxtla y todo Chiapas alzaron su voz para poner un alto a la subordinación a la metrópoli europea. Esta es, sin duda, una diferencia que merece atención, pero que en modo alguno demerita el hecho mismo de la vocación libertaria de nuestro pueblo [mexicano]"'.

11 El discurso de Villegas Megías reconoce el 28 de agosto de 1821 como el comienzo "en Chiapas y en todo Centroamérica [de] un proceso profundo de transformación de la vida pública". Además de señalar que, tanto la independencia de Comitán como la de la Nueva España, fue el resultado de un pacto de las élites para separarse de la tutela española e iniciar un proceso fundacional, "al tiempo que postergaba de manera indefinida las reivindicaciones de carácter social", relegando a un segundo plano "los anhelos de justicia social por los que también muchas personas se entregaron en cuerpo y alma”. Estas élites buscaron la independencia con el fin de mantener sus fueros y privilegios, "como siempre lo hacen los grupos poderosos con el pensamiento conservador".

Debido al "vergonzoso" germen del acto emancipador, el gobernador chiapaneco y el presidente López Obrador dieron poco espacio en sus discursos al hecho histórico. En cambio, reivindicaron al senador Belisario Domínguez y la escritora Rosario Castellanos, ambas figuras del siglo xx de origen comiteco, vinculando su lucha y obra con el momento actual: "cambiamos de una política de poder a una política de servir. Con la Cuarta Transformación de la vida pública tenemos una fuerza motriz para impulsar el desarrollo de Chiapas".

13 Cabe rescatar el discurso de Zoé Robledo Aburto (presidente de la Comisión presidencial para la conmemoración de hechos, procesos y personajes históricos de México), quien señaló que la firma del acta de independencia en Comitán es el inicio de 
una nueva etapa en el territorio, marcada por el alejamiento del Reino de Guatemala y su ingreso al proceso histórico mexicano. Para Robledo la "mexicanidad" de Chiapas llega a su cúspide en 1824, cuando el territorio se anexa definitivamente a la República Federal Mexicana. De este modo: "el sentimiento chiapaneco se fue enriqueciendo con un importante contenido de sentimiento mexicano".

Sin embargo, probablemente el evento más destacado, en la coyuntura de la conmemoración del Bicentenario de la Independencia en Chiapas, fue el Congreso Centroamericano de Historia: ese encuentro académico organizado por la Universidad de Ciencias y Artes de Chiapas y El Colegio de Michoacán debió realizarse en Tuxtla Gutiérrez, capital del estado, pero debido a la contingencia sanitaria se efectuó de manera virtual. El Congreso abrió al menos tres espacios especiales para reflexionar la consumación de la independencia de 1821, mediante el análisis de balances historiográficos y políticos, para plantear un revisionismo de ese hecho. De esta forma, destacó la crítica al uso ideológico de la fecha y la falta de agendas gubernamentales que busquen remediar los atrasos sociales, económicos y políticos que aún persisten en las naciones centroamericanas y Chiapas.

El sector académico, las asociaciones civiles y algunos gobiernos municipales asumieron la tarea de organizar encuentros, conversatorios y conferencias especiales, las cuales retoman desde la historia las implicaciones de la consumación de la independencia para Chiapas. Así, el ayuntamiento de Tapachula organizó un ciclo de conferencias sobre el Bicentenario en Chiapas, pero enfatizando en la mirada regional del Soconusco, a manera de reivindicación social y cultural. También, centros de investigación locales como el CIMSUR, CESMECA y CIESAS prepararon discusiones entre investigadores de alto nivel para reflexionar y problematizar el bicentenario.

Finalmente, un aspecto que sin duda quedará para la historia de la celebración del segundo centenario, será la modalidad virtual de la mayoría de los encuentros. Esto permitió que se llegara remotamente a otros lugares y a más público, evitando el riesgo sanitario y formando parte de este momento especial, en espera del próximo bicentenario: la anexión de Chiapas a México en 2024.

\section{BIBLIOGRAFÍA}

Méndez Zárate, Armando, “Apuntes para la historia comparada de la independencia del Reino de Guatemala, 1808-1821", en Elizeth Payne y Sajid Herrera (dir.), La justa libertad de los pueblos. Las independencias en Centroamérica, Chiapas y Panamá, Madrid, Editorial SILEX Ultramar, Asociación Cultural Española, 2021, pp. 55-84

Sánchez Lima, José Enrique, “La incorporación política del Soconusco a la República mexicana: una historia multifactorial (1824-1842), Revista pueblos y fronteras digital, vol. 15, 2020, p. 1-31.

Vázquez Olivera, Mario, El Imperio Mexicano y el Reino de Guatemala. Proyecto político y campaña militar, 1821-1823, México, Fondo de Cultura Económica, CIALC-UNAM, 2009. 
Vázquez Olivera, Mario, Chiapas, años decisivos. Independencia, unión a México y primera república federal, Tuxtla Gutiérrez, UNICACH, 2010.

\section{NOTAS}

1. Gobierno de México, "Exceso de Mortalidad en México" en Coronavirus.gob.mx: https:// coronavirus.gob.mx/exceso-de-mortalidad-en-mexico/ (página consultada el 30 de agosto de 2021).

2. El exceso estimado es interpretado como defunciones tanto directamente asociadas al Covid-19, como por otras causas que indirectamente pueden ser asociadas a la situación general de la emergencia sanitaria.

3. Mario Vázquez Olivera, El Imperio Mexicano y el Reino de Guatemala. Proyecto político y campaña militar, 1821-1823, México, Fondo de Cultura Económica, CIALC-UNAM, 2009.

4. "Voz pública. Celebran Gesta Heroica de los Niños Héroes de Chapultepec; inician festejos patrios en Chiapas", en AquíNoticias: https://aquinoticias.mx/celebran-gesta-heroica-de-losninos-heroes-de-chapultepec-inician-festejos-patrios-en-chiapas/ (página consultada el 27 de septiembre de 2021).

5. Entre los miembros fundadores se encuentran Roberto Ramos Maza (actual subsecretario de Promoción Turística de la Secretaría de Turismo de Chiapas), José Javier Bautista Ruiz (director del Centro Universitario Mesoamericano), José Luis Castro Aguilar (cronista, cuentistay poeta chiapaneco) y Leticia Zepeda Pineda (cantante de ópera).

6. Agradecemos la entrevista que nos otorgó al respecto Carlos Román García, el día 31 de agosto de 2021. Para conocer más de la asociación Bicentenario de Chiapas A.C., visitar la página: http:// bicentenariochiapas.org/

7. La Coordinación Nacional de Memoria Histórica y Cultural de México es una iniciativa de la esposa del presidente de México, Beatriz Gutiérrez Müller, cuyo objetivo es preservar y difundir materiales relativos a la historia nacional a través de la página web Memórica. México, haz memoria. Ver: https://memoricamexico.gob.mx/es/memorica/Haz_memoria

8. Presidencia de la República, 200 años. Conmemoración del Bicentenario de la Independencia de Chiapas de la Corona Española, 1821-2021, 28 de agosto de 2021, en Gobierno de México: https:// www.gob.mx/presidencia/es/articulos/version-estenografica-200-anos-conmemoracionbicentenario-de-la-independencia-de-chiapas-de-la-corona-espanola-1821-2021?idiom=es (página consultada el 30 de agosto de 2021).

9. Ibid.

\section{AUTORES}

\section{AMANDA ÚRSULA TORRES FREYERMUTH}

Amanda Úrsula Torres Freyermuth es doctora en Historia e investigadora de tiempo completo del Centro de Investigaciones Multidisciplinarias sobre Chiapas y la Frontera Sur de la Universidad Nacional Autónoma de México. Ha dedicado su vida profesional al estudio de los procesos políticos, económicos y sociales de Chiapas en el siglo XIX. 


\section{ARMANDO MÉNDEZ ZÁRATE}

Armando Méndez Zárate es doctor en Historia por el Centro de Investigaciones y Estudios Superiores en Antropología Social. Su obra se ha enfocado en la historia comparada de Chiapas y Centroamérica durante el siglo XIX, sobre temas agrarios, formación del estado y fronteras. 